\title{
Biocontrole dos extratos de Hovenia dulcis e Ateleia glazioviana frente a organismos xilófagos
}

\author{
Biocontrol of the extracts of Hovenia dulcis and Ateleia glazioviana against \\ xylophagus organisms
}

\author{
Maiara Talgatti ${ }^{1}$ (D), Amanda Grassmann da Silveira ${ }^{1}$ (D), Talita Baldin² (D), Guilherme Valcorte ${ }^{1}$ (D), \\ Elio José Santini ${ }^{1}$ (1) \\ ${ }^{1}$ Universidade Federal de Santa Maria - UFSM, Santa Maria, RS, Brasil \\ 2Universidade Federal de Minas Gerais - UFMG, Montes Claros, MG, Brasil
}

Como citar: Talgatti, M., Silveira, A. G., Baldin, T., Valcorte, G., \& Santini, E. J. (2020). Biocontrole dos extratos de Hovenia dulcis e Ateleia glazioviana frente a organismos xilófagos. Scientia Forestalis, 48(125), e3241. https://doi.org/10.18671/scifor.v48n125.17

\begin{abstract}
Resumo
Objetiva-se verificar a toxidez dos extratos aquosos dos materiais lignocelulósicos (madeira, casca e folhas) de Hovenia dulcis e Ateleia g/azioviana aos principais organismos xilófagos da madeira. Para tal, foram cortadas cinco árvores de cada espécie, e obtidos os materiais vegetais para a confecção dos extratos aquosos. Esses foram incorporados ao meio de cultura em placas de petri a fim de verificar a toxidez de dois fungos deterioradores Pycnoporus sanguineus e Gloeophyllum trabeum. As avaliações do experimento foram iniciadas 24 horas após a inoculação, por meio de medições diárias do crescimento micelial, até que as placas testemunhas fossem tomadas pelos fungos. Os extratos foram testados também como bioinseticidas no controle de térmitas, para isso, em placas de petri foram postos papéis filtro impregnados com extratos e após adicionadas 20 térmitas ativas em cada placa, que permaneceram em incubadora a $28 \pm 2^{\circ} \mathrm{C}, 75 \pm 5$. Em cada placa foi calculada a porcentagem de mortalidade dos cupins por $2 \mathrm{~h}$ e $24 \mathrm{~h}$. Todos extratos aquosos de Hovenia dulcis e Ateleia glazioviana possuem potencial fungitóxico frete aos fungos representantes da podridão branca e parda e potencial pesticida frente às térmitas. Em geral, os extratos aquosos de Ateleia glazioviana mostraram-se de melhor desempenho em relação aos de Hovenia dulcis, podendo vir a serem empregados futuramente como biopreservantes de madeiras.
\end{abstract}

Palavras-chave: Fungitoxidade; Controle alternativo; Extratos aquosos.

\begin{abstract}
The present study aims to verify the toxicity of aqueous extracts of the wood, bark and leaves lignocellulosic materials of Hovenia dulcis and Ateleia glazioviana to the main woody xylophagous organisms. For this, five trees of each species were felled, of these, the vegetal materials were obtained for the preparation of the aqueous extracts of the wood. The extracts were incorporated into the culture medium in petri dishes in order to verify the toxicity to the main deteriorated fungi of Pycnoporus sanguineus and Gloeophyllum trabeum woods. Experiment evaluations were initiated 24 hours after inoculation by daily measurements of mycelial growth until the control plaques were taken up by the fungi. In addition, the extracts were also tested as bioinsecticides in the control of termites. For this purpose, filter papers impregnated with the extracts were placed in petri dishes and after addition of 20 active termites in each plate, which were incubated at $28 \pm 2{ }^{\circ} \mathrm{C}, 75 \pm 5$. There were five replicates per treatment, and for each plate, mortality rate of termites was calculated for $2 \mathrm{~h}$ and $24 \mathrm{~h}$ for each treatment. All aqueous extracts of Hovenia dulcis and Ateleia glazioviana have fungitoxic potential freight to fungi representative of white and brown rot and potential pesticide against termites. In general, the extracts of Ateleia glazioviana showed to be of better fungitoxic performance and pesticide in relation to those of Hovenia dulcis, and could be used as biopreservantes of wood.
\end{abstract}

Keywords: Fungitoxic; Alternative control; Watery extracts.

Fonte de financiamento: Bolsa de Doutorado do Cnpq

Conflito de interesse: Nada a declarar.

Autor correspondente: maiara.talgatti@hotmail.com

Recebido: 7 janeiro 2019.

Aceito: 6 maio 2019.

Editor: Francides Gomes da Silva Júnior.

(c) (1) Este é um artigo publicado em acesso aberto (Open Access) sob a licença Creative Commons Attribution, que permite uso, distribuição e reprodução em qualquer meio, sem restrições desde que o trabalho original seja corretamente citado. 


\section{INTRODUÇÃO}

A madeira é um material renovável cujas propriedades físico-mecânicas, químicas e anatômicas a tornam versátil e amplamente utilizada em todo o mundo (Vidal et al., 2015). Porém, por ser biológico e degradável, a madeira está sujeita à mudança de suas propriedades e de sua resistência natural frente a agentes bióticos e abióticos (Brocco et al., 2017). O tratamento preservativo vem a ser imprescindível para madeiras de baixa durabilidade natural ou para porções permeáveis e passíveis de tratamento, como o alburno (Vidal et al, 2015). A literatura é clara em afirmar: a partir da baixa resistência natural a organismos xilófagos, torna-se necessária a impregnação da madeira com produtos químicos, aumentando seu tempo útil de uso (Paes et al., 2005).

Grande parte das madeiras de baixa durabilidade natural são tratadas por métodos industriais sob vácuo e pressão, com preservativos hidrossolúveis constituídos por sais metálicos que têm alta eficiência no processo de proteção da madeira a organismos xilófagos (Lebow, 2010). Os preservativos mais utilizados são o arseniato de cobre cromatado e o borato de cobre cromatado, conhecidos respectivamente como CCA e CCB (Kartal et al., 2015). Porém, de acordo com Vidal et al. (2015) o uso do CCA já é restrito em alguns países, devido à presença de arsênio na sua formulação, que é um elemento nocivo à saúde humana. Os autores supracitados ainda destacam que além das preocupações sobre os riscos de produtos à base de arsênio e cromo na saúde humana, existem também preocupações sobre os impactos desses produtos no meio ambiente. Sendo assim, torna-se pertinente os estudos e desenvolvimento de novas alternativas para tratamento de madeiras que sejam menos tóxicos aos organismos não xilófagos e ao meio ambiente.

A busca por preservativos de madeiras menos tóxicos ao ambiente é constante na literatura, autores como Brocco et al. (2017), Modes et al. (2017), Silveira et al. (2017) vêm pesquisando alternativas naturais como extratos, óleos essenciais e até mesmo termorretificação para a substituição dos preservantes tradicionais. Corroborando, Kirker et al. (2013) destacam que a utilização de extratos botânicos podem elevar a durabilidade de madeiras propensas ao apodrecimento.

Sendo assim, o objetivo do presente estudo foi verificar a toxidez de extratos aquosos de materiais lignocelulósicos (madeira, casca e folhas) de Hovenia dulcis (uva-do-Japão) e Ateleia glazioviana (timbó) aos principais organismos xilófagos da madeira.

\section{MATERIAL E MÉTODOS}

\section{Obtenção do material vegetal e dos extratos}

As árvores de Hovenia dulcis e Ateleia glazioviana são provenientes de plantações experimentais do Departamento de Diagnóstico e Pesquisa Agropecuária-DDPA- Santa Maria-RS. Foram abatidas cinco árvores de cada espécie e selecionadas as primeiras toras com $3 \mathrm{~m}$, destas, foram retiradas as cascas e os discos que, posteriormente, foram reduzidos a lascas utilizando uma guilhotina. Já as folhas foram colhidas das copas das árvores e moídas em liquidificador industrial. O material lignocelulósico para a obtenção dos extratos (Figura 1) foi seco a temperatura ambiente por 15 dias. 


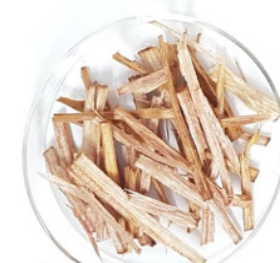

A

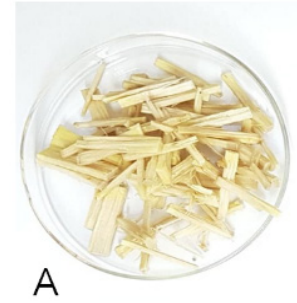

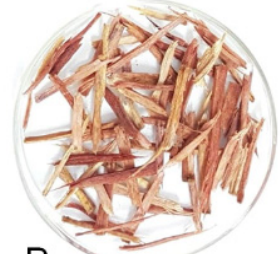

B

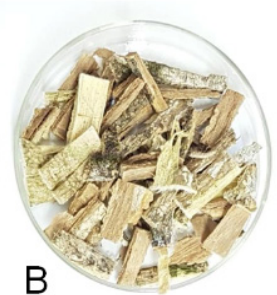

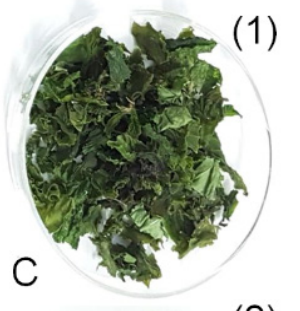

(2)

Figura 1- Materiais lignocelulósicos de Hovenia dulcis (1) e Ateleia glazioviana (2), madeira (A), casca (B) e folhas (C).

Após, 200 gramas de madeira, casca e folhas, secos ao ar livre por 15 dias, de cada espécie, foram colocadas separadamente em copos de Becker com 2 litros de água destilada e então, fervidos por duas horas utilizando chapa aquecedora, com $10 \%$ de concentração, o material foi então passado em peneira para a filtragem dos extratos aquosos.

\section{Ensaio em meio de cultura com fungos}

O experimento foi composto pelo tratamento testemunha, que serviu como referência, e por três tratamentos, com 5 repetições cada, utilizando os extratos obtidos das folhas, casca e madeira de Hovenia dulcis e Ateleia glazioviana. Os tratamentos foram individualmente incorporados ao meio de cultura, e após foram vertidos em placas de Petri. Em seguida, houve a inoculação dos fungos Pycnoporus sanguineus - PS (agente causador da podridão branca em madeiras) e Gloeophyllum trabeum - GT (agente causador da podridão parda em madeiras) nas placas, a qual foi realizada com auxílio de tubos de ensaio de $8 \mathrm{~mm}$ de diâmetro (confecção de discos da colônia) e agulha, esta que auxiliou na transferência do disco para o centro de cada placa, sendo realizada a vedação e evitando contaminação. Posteriormente as placas foram mantidas em ambiente com temperatura e fotoperíodo controlado até que o tratamento $0 \%$ (testemunha) preenchesse a primeira placa. $\mathrm{O}$ ambiente mantinha-se climatizado a $25^{\circ} \mathrm{C}, 75 \pm 5 \%$ de UR e fotofase de 12 horas.

As avaliações do experimento foram iniciadas 24 horas após a inoculação, por meio de medições diárias do crescimento micelial, até que as placas testemunhas fossem tomadas pelos fungos, cerca de seis dias para o fungo PS e oito dias para o fungo GT, sendo que cada medição correspondeu à média de duas medidas diametralmente opostas da colônia fúngica, mediante o uso de paquímetro. $O$ índice de crescimento micelial (ICM) e a porcentagem de inibição de crescimento (PIC) foram calculados, respectivamente, pelas fórmulas apresentadas nas Equações 1 e 2.

Onde: $\mathrm{C1}, \mathrm{C2}, \mathrm{Cn}$ = crescimento micelial das colônias na primeira, segunda e última avaliação e N1, N2, Nn = número de dias.

$$
\mathrm{PIC}=\frac{(\mathrm{DTe}-\mathrm{DTr})}{\mathrm{DTe}} * 100
$$

Onde: $\mathrm{DTe}=$ diâmetro da testemunha e DTr = diâmetro do tratamento. 


\section{Ensaio laboratorial comtérmitas}

Para o ensaio laboratorial com térmitas, preparou-se concentrações iguais aquelas avaliadas na atividade fungitóxica. Logo, papéis filtro foram submersos nas soluções contento os diferentes extratos e em água, esta última para o tratamento controle (Testemunha), em seguida colocados em placas de petri juntamente com 20 térmitas ativas (18 operários e 2 soldados) de Nasutitermes sp., conforme Figura 2. As placas permaneceram em incubadora a $28 \pm 2{ }^{\circ} \mathrm{C}, 75 \pm 5 \%$ de UR. Foram cinco repetições por tratamento, e para cada placa foi calculada porcentagem de mortalidade dos cupins por $2 \mathrm{~h}$ e $24 \mathrm{~h}$.

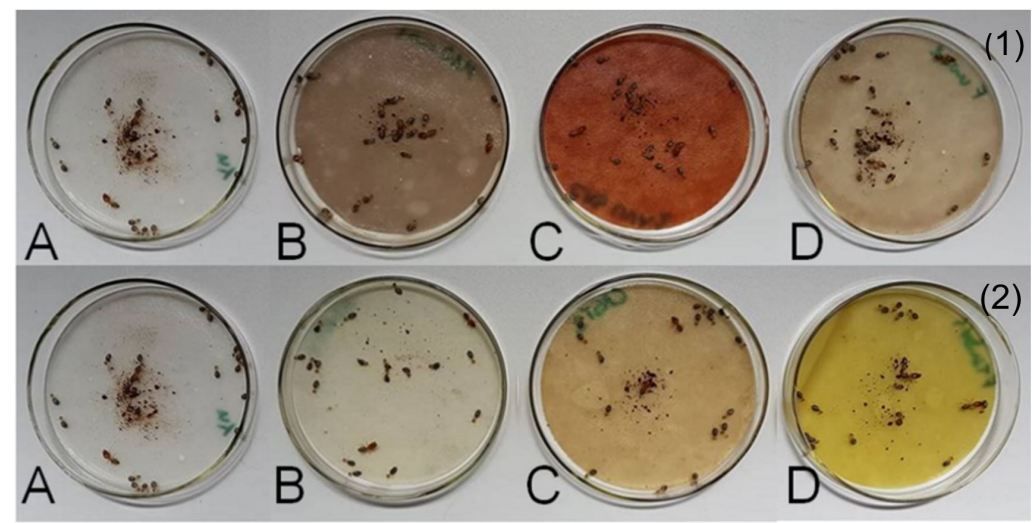

Figura 2- Aspecto visual das placas de petri contendo papel filtro umedecido com os extratos aquosos obtidos dos diferentes materiais lignocelulósicos de Hovenia dulcis (1) e Ateleia glazioviana (2). Onde:testemunha (A), madeira (B), casca (C) e folhas (D) sob térmitas.

\section{Análise estatística}

Os dados das propriedades foram avaliados com o auxílio do software estatístico Genes (Cruz, 2001), em arranjo bifatorial $4 \times 2$ (quatro tratamentos, sendo três extratos de madeira, casca e folhas dois fungos, Pycnoporus sanguineus e Gloeophyllum trabeum) para cada uma das duas espécies avaliadas (Hovenia dulcis e Ateleia glazioviana). Havendo interação significativa entre os fatores, as médias foram comparadas pelo teste $t$ ( $5 \%$ de probabilidade). Onde não houve interação significativa entre os fatores, as médias de cada fator foram avaliadas pelo teste de Tukey ( $5 \%$ de probabilidade).

\section{RESULTADOS E DISCUSSÃO}

Os índices médios de crescimento micelial de Pycnoporus sanguineus e Gloeophyllum trabeum decresceram com a adição dos extratos naturais derivados dos materiais lignocelulósicos de Hovenia dulcis ao meio de cultura, indicando toxidez dos mesmos a estes fungos (Tabela 1). Ainda na Tabela 1 é possível visualizar o percentual de inibição de crescimento dos fungos em contato com os extratos, a redução do crescimento ocorreu no intervalo médio de 42,34 a $65,59 \%$. O fungo Gloeophyllum trabeum é mais sensível aos extratos apresentando a maior redução de crescimento.

Tabela 1 - Índice de Crescimento Micelial (ICM) dos fungos PS (Pycnoporus sanguineus) e GT (Gloeophyllum trabeum) frente aos extratos lignocelulósicos de Hovenia dulcis e as diferentes Porcentagens de Inibição de Crescimento (PIC).

\begin{tabular}{ccccc}
\hline Tratamento & ICM PS & PIC (\%) & ICM GT & PIC (\%) \\
\hline Testemunha & $43,12 \mathrm{bA}$ & - & $43,89 \mathrm{cA}$ & - \\
Madeira & $14,14 \mathrm{aA}$ & 53,39 & $10,36 \mathrm{aA}$ & 65,77 \\
Casca & $11,92 \mathrm{aA}$ & 53,61 & $12,02 \mathrm{aA}$ & 59,59 \\
Folha & $15,03 \mathrm{aA}$ & 52,85 & $24,90 \mathrm{bB}$ & 42,34 \\
\hline
\end{tabular}

*Médias seguidas pela mesma letra maiúscula na linha e minúscula na coluna não diferem entre si pelo teste $T$ à $5 \%$ de probabilidade. 
Trabalhos que utilizaram extratos de árvores como biopreservantes no controle de deterioradores de madeiras ainda são incipientes. Porém, Venturoso et al. (2011) estudando extratos vegetais aquosos para o combate de fungos fitopatogênicos da soja observaram que houve diferenças significativas em relação à testemunha para crescimento micelial de Cercospora kikuchii, com extratos de hortelã, arruda e melão de São Caetano, na concentração de $20 \%$, mesma concentração utilizada no presente estudo. Corroborando Nascimento et al. (2013), também relatam o potencial tóxico de extratos aquosos de calêndula, hortelã, arruda, e melão de São Caetano em diferentes concentrações sobre o crescimento micelial de Cercospora calendulae (fungo causador de mancha foliar em plantas de calêndula) na ordem de 100\%, 30\%, 35\% e 40\%, respectivamente, na maior concentração utilizada, $10000 \mathrm{mg} \mathrm{L}^{\mathrm{L}-1}$.

Os índices de crescimento micelial do Pycnoporus sanguineus frente aos extratos mostraram-se semelhantes, sem diferença estatística em todos os tratamentos. Já para Gloeophyllum trabeum apenas o extrato com folhas diferenciou-se. Todos os extratos, independente da parte vegetal utilizada, apresentaram toxidez a ambos os fungos sem diferença estatística entre eles, excetuando-se o de folhas incorporado ao meio de cultura do fungo GT o qual mostrou resultado menos eficaz em relação aos demais, indicando que no futuro o desenvolvimento de biopreservantes deve priorizar as partes lenhosas de Hovenia dulcis.

O aspecto visual do crescimento micelial dos fungos é ilustrado na Figura 3, onde é possível visualizar a redução do crescimento micelial dos fungos PS e GT em contato com os meios de culturas incorporados aos extratos testados de Hovenia dulcis.

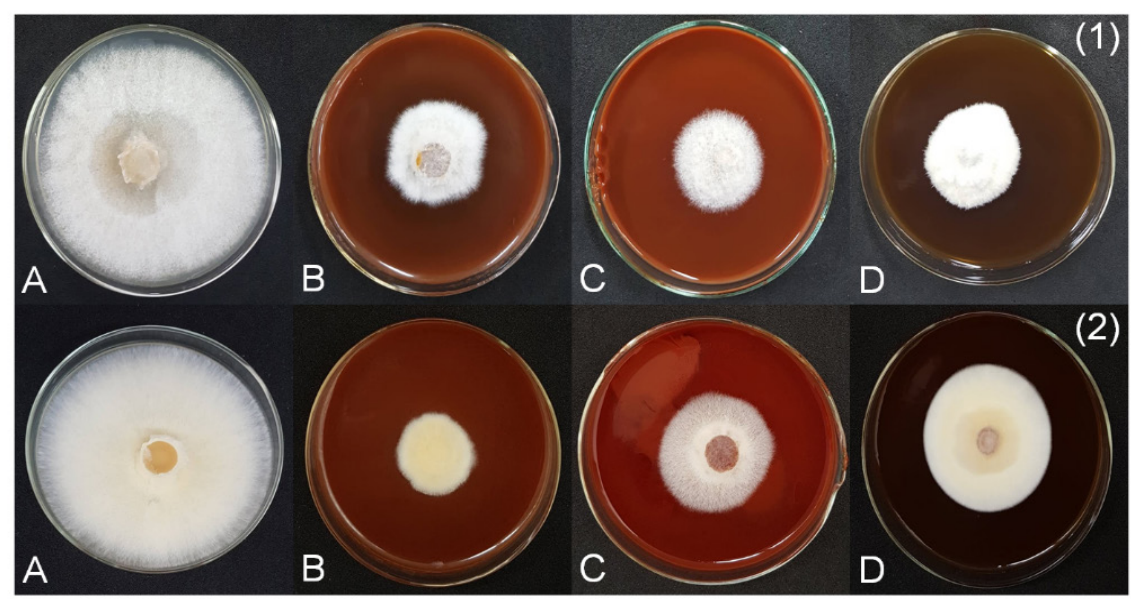

Figura 3 - Aspecto visual das placas contendo os extratos aquosos dos materiais lignocelulósicos de Hovenia dulcis e testemunha (A), madeira (B), casca (C) e folha (D), com os fungos (1) Pycnoporus sanguineus e (2) Gloeophyllum trabeum.

A maior taxa de crescimento micelial das colônias dos fungos ocorreu com o Pycnoporus sanguineus (Figura 4A), que em 120 horas o crescimento das testemunhas preencheu as placas, já para o fungo Gloeophyllum trabeum este processo ocorreu em maior tempo, 168 horas. Destaca-se a menor velocidade de crescimento em todos os tratamentos utilizados, assinalando o potencial inibidor de desenvolvimento dos fungos em relação aos extratos utilizados. 

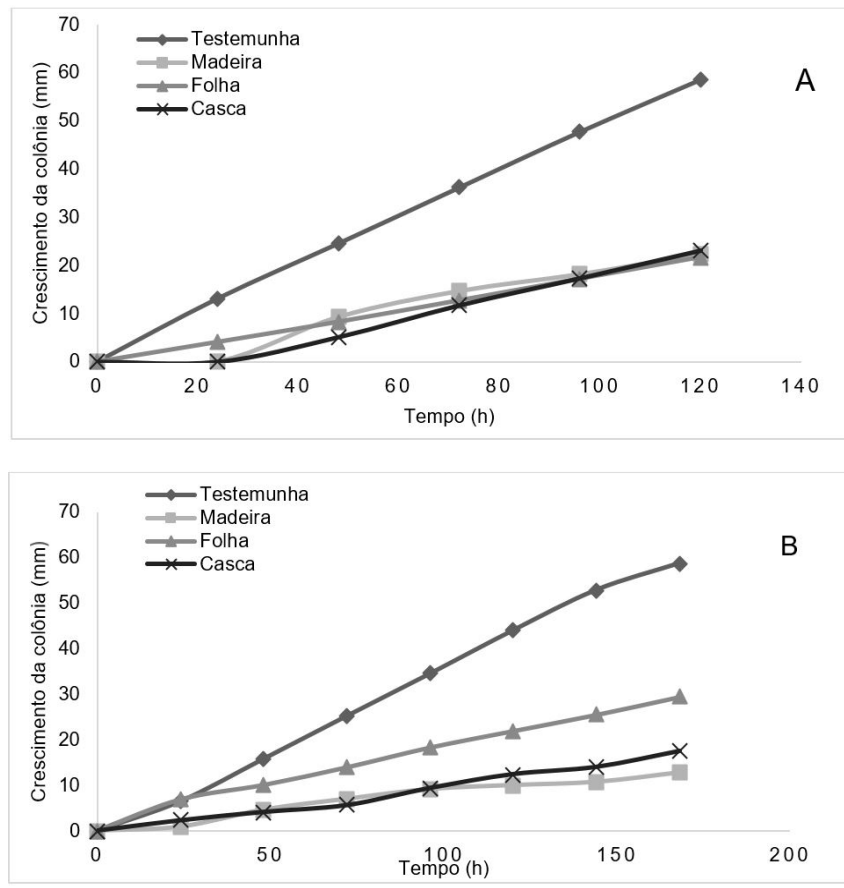

Figura 4- A- Efeito dos diferentes extratos lignocelulósicos de Hovenia dulcis incorporado ao meio BDA sobre o crescimento micelial de Pycnoporus sanguineus e B- Gloeophyllum trabeum.

Na Tabela 2 é possível visualizar os dados obtidos referentes ao crescimento micelial de Pycnoporus sanguineus e Gloeophyllum trabeumem contato com os extratos naturais obtidos da Ateleia glazioviana. O crescimento micelial de ambos os fungos apresentou redução, esses resultados corroboram com o percentual de inibição de crescimento, o qual obteve valores médios de 27 chegando até $84,68 \%$. A melhor inibição ocorreu no emprego do extrato da casca de $A$. glazioviana no ensaio com o fungo PS, onde ocorreu a maior redução de crescimento, $84,68 \%$.

Tabela 2 - Índice de Crescimento Micelial (ICM) dos fungos PS (Pycnoporus sanguineus) e GT (Gloeophyllum trabeum) frente aos extratos lignocelulósicos de Ateleia glazioviana e as diferentes Porcentagens de Inibição de Crescimento (PIC).

\begin{tabular}{ccccc}
\hline Tratamento & ICM PS & PIC (\%) & ICM GT & PIC (\%) \\
\hline Testemunha & $34,18 \mathrm{cA}$ & - & $43,89 \mathrm{dA}$ & - \\
Madeira & $4,18 \mathrm{aA}$ & 71,10 & $10,47 \mathrm{aB}$ & 63,18 \\
Casca & $1,59 \mathrm{aA}$ & 84,68 & $15,10 \mathrm{bB}$ & 57,74 \\
Folha & $13,68 \mathrm{bA}$ & 43,75 & $30,51 \mathrm{cB}$ & 27,66 \\
\hline
\end{tabular}

*Médias seguidas pela mesma letra maiúscula na linha e minúscula na coluna não diferem entre si pelo teste T à 5\% de probabilidade.

Os resultados do ICM para o fungo Pycnoporus sanguineus apresentaram diferença estatística entre o extrato das folhas em relação aos demais, tendência semelhante com Gloeophyllum trabeum. Porém, quando olhamos entre os fungos, o representante da podridão parda mostra-se mais resistente aos extratos em relação ao causador da podridão branca, que apresentou resultados muito melhores com menor crescimento em todos os tratamentos utilizados. $O$ aspecto visual do crescimento micelial dos fungos pode ser visto na Figura 5. 


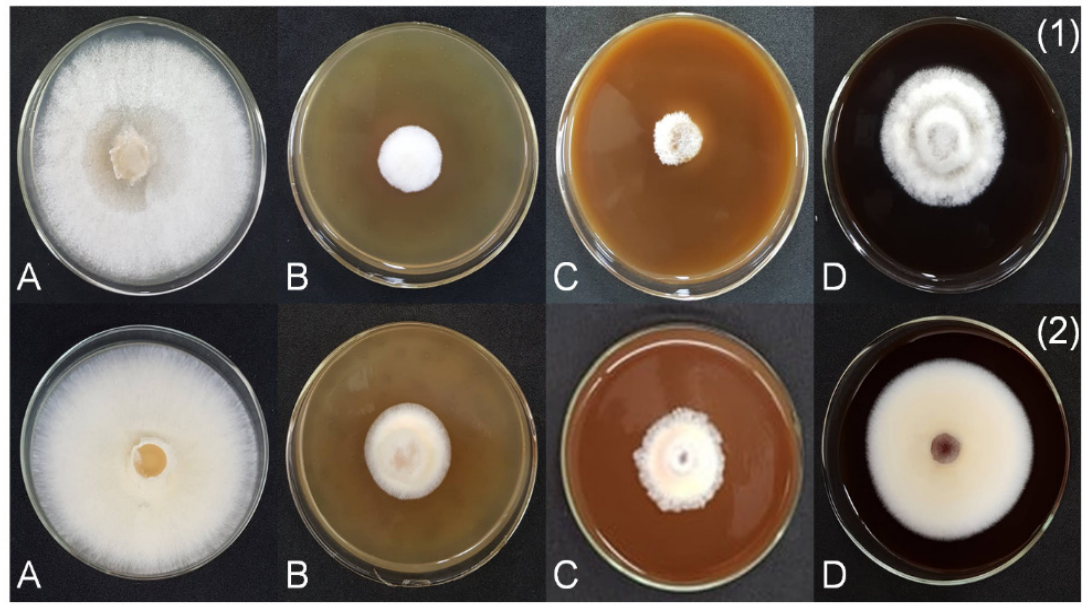

Figura 5 - Aspecto visual das placas contendo os extratos aquosos dos materiais lignocelulósicos de Ateleia glazioviana e testemunha (A), madeira (B), casca (C) e folha (D), com os fungos (1) Pycnoporus sanguineus e (2) Gloeophyllum trabeum

Silveira et al. (2017) em estudos com extrato natural da Acacia mearnsii, verificaram em concentrações de 4 e $5 \%$ índice de crescimento micelial semelhantes ao resultado obtido para o extrato aquoso da madeira e casca de Ateleia glazioviana frente ao fungo Pycnoporus sanguineus. Porém, a concentração dos extratos lignocelulósicos utilizados no presente estudo é de $10 \%$, em concentrações maiores os extratos poderiam apresentar melhores resultados.

Destaca-se na Figura 6A o potencial inibidor de desenvolvimento do fungo PS no tratamento utilizando o extrato da casca de Ateleia glazioviana, que apresentou a curva menos acentuada de crescimento do diâmetro da colônia fungal. Já na Figura 6B, visualiza-se as curvas semelhantes de crescimento do fungo GT nos tratamentos utilizando os extratos da madeira e da casca de A. glazioviana. Este resultado mostra consonância com os dados anteriormente apresentados na Tabela 2.
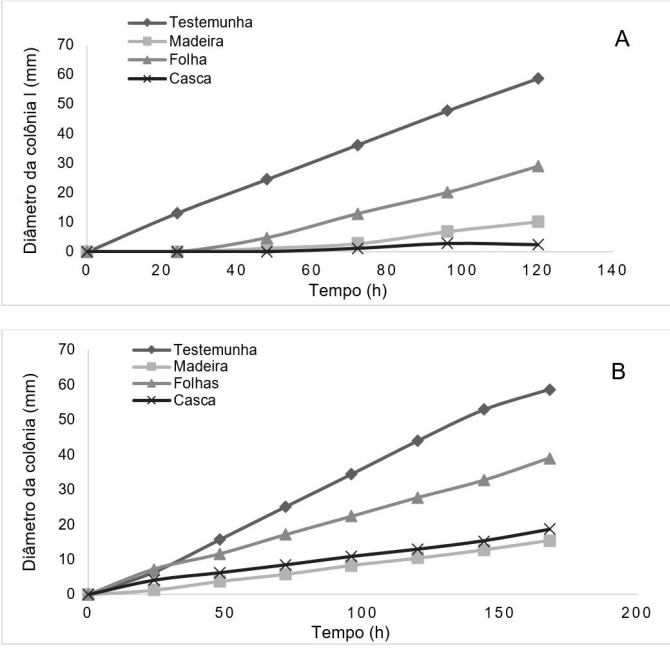

Figura 6- A- Efeito dos diferentes extratos lignocelulósicos de Ateleia glazioviana incorporado ao meio BDA sobre o crescimento micelial de Pycnoporus sanguineus e B- Gloeophyllum trabeum.

Quanto a mortalidade de térmitas no ensaio de atividade anti-térmitas em 2 e 24 horas, é possível visualizar que os extratos possuem potencial biopesticida, em especial o extrato da madeira de Ateleia glazioviana o qual proporcionou a mortalidade de $77,5 \%$ dos cupins passadas 24 horas (Tabela 3). Quanto aos demais, não houve diferença estatística entre eles, 
exceto para o extrato das folhas de Ateleia glazioviana que apresentou a menor taxa de mortalidade de térmitas, 56,25\% em 24 horas. Em média, após 24 horas de ensaio os extratos de ambas as espécies estudadas apresentaram mais de 60\% de mortalidade em térmitas. Sharma et al. (2013) avaliando o potencial biopesticida de extratos de sementes de Azadirachta indica contra cupins, em concentrações de 10\%, apresentaram o porcentual de mortalidade de quase $60 \%$ em 24 horas, resultado semelhante aos do presente estudo.

Tabela 3- Mortalidade de térmitas em duas e 24 horas.

\begin{tabular}{cccc}
\hline & & \multicolumn{2}{c}{ Mortalidade (\%) } \\
\cline { 3 - 4 } & & $\mathbf{2}$ horas & $\mathbf{2 4}$ horas \\
\hline \multirow{2}{*}{ Testemunha } & - & $0 \mathrm{~b}$ & $15 \mathrm{c}$ \\
Hovenia dulcis & Madeira & $22,5 \mathrm{a}$ & $66,25 \mathrm{ab}$ \\
& Casca & $3,75 \mathrm{ab}$ & $61,25 \mathrm{ab}$ \\
\multirow{2}{*}{ Ateleia glazioviana } & Folha & $8,75 \mathrm{ab}$ & $60 \mathrm{ab}$ \\
& Madeira & $30 \mathrm{a}$ & $77,5 \mathrm{a}$ \\
& Casca & $1,25 \mathrm{~b}$ & $62,5 \mathrm{ab}$ \\
& Folha & $13,75 \mathrm{ab}$ & $56,25 \mathrm{~b}$
\end{tabular}

*Médias seguidas pelas mesmas letras nas colunas não diferem entre si pelo teste Tà $5 \%$ de probabilidade.

Os pesquisadores Cruz et al. (2009) analisando o efeito de cinco pós vegetais sobre a mortalidade de cupins Nasutitermes sp., utilizando metodologia semelhante, verificaram após quatro dias de ensaio resultados de mortalidade de térmitas inferiores aos apresentados neste estudo passadas 24 horas. Os autores supracitados, aferiram que o tratamento com pó das sementes de Aspidosperma pyrifolium obteve maior eficiência no controle (44,90\%) dos cupins Nasutitermes sp., quando comparado aos demais tratamentos com pó de sementes de pinhão bravo (Jatropha pohliana), velame (Croton sp.), feijão-bravo (Capparis flexuosa) e pinha (Annona squamosa) Mesmo assim, estes resultados mostram inferioridade quando comparados ao pior desempenho do presente estudo, advindo do extrato de folha de Ateleia glazioviana $(50,25 \%)$.

\section{CONCLUSÃO}

- Todos extratos aquosos de Hovenia dulcis e Ateleia glazioviana possuem potencial fungitóxico frete aos fungos representantes da podridão branca e parda;

- $\quad$ Os extratos possuem potencial pesticida frente às térmitas;

- Em geral, os extratos de Ateleia glazioviana mostraram-se de melhor desempenho fungitóxico e pesticida em relação aos de Hovenia dulcis, podendo vir a serem empregados como biopreservantes de madeiras;

- Tendo em vista os resultados positivos obtidos, sugere-se que em estudos futuros, verifique-se a compatibilidade e combinação dos extratos estudados com preservantes naturais já desenvolvidos.

\section{REFERÊNCIAS BIBLIOGRÁFICAS}

Brocco, V. F., Paes, J. B., Costa, L. G., Brazolin, S., \& Arantes, M. D. C. (2017). Potential of teak heartwood extracts as a natural wood preservative. Journal of Cleaner Production, 142(4), 2093-2099. http://dx.doi.org/10.1016/j.jclepro.2016.11.074.

Cruz, C. D. (2001). Programa genes - aplicativo computacional em genética e estatística (Vol. 1, pp. 442). Viçosa: Editora UFV.

Cruz, C. S. A., Medeiros, M. B., \& Wanderley, M. J. A. (2009). Efeito de cinco pós vegetais sobre a mortalidade de cupins Nasutitermes sp. (Isoptera: termitidae). Revista de Biologia e Ciências da Terra, $1,15-18$

Kartal, S. N., Terzi, E., Yilmaz, H., \& Goodell, B. (2015). Bioremediation and decay of wood treated with ACQ, micronized ACQ, nano-CuO and CCA wood preservatives. International Biodeterioration \& Biodegradation, 99, 95-101. http://dx.doi.org/10.1016/j.ibiod.2015.01.004. 
Kirker, G. T., Blodgett, A. B., Arango, R. A., Lebow, P. K., \& Clausen, C. A. (2013). The role of extractives in naturally durable wood species (Vol. 82, p. 53-58). Birmingham: International Biodeterioration \& Biodegradation.

Lebow, S. T. (2010). Wood preservation. In United States Department of Agriculture. Wood handbook: woos as an engineering material (chap. 15). Madison: Forest Products Laboratory.

Modes, K. S., Santini, E. J., Vivian, M. A., \& Haselein, C. R. (2017). Efeito da termorretificação nas propriedades mecânicas das madeiras de Pinus taeda e Eucalyptus grandis. Ciência Florestal, 27(1), 291-302. http://dx.doi.org/10.5902/1980509826467.

Nascimento, J. M., Serra, A. P., Bacchi, L. M., Gavassoni, W. L., \& Vieira, M. C. (2013). Inibição do crescimento micelial de Cercospora calendulae Sacc. por extratos de plantas medicinais. Revista Brasileira de Plantas Medicinais, 15(4), 751-756. http://dx.doi.org/10.1590/S151605722013000500016.

Paes, J. B., Moreschi, J. C., \& Lelles, J. G. (2005). Avaliação do tratamento preservativo de moirões de Eucalyptus viminalis Lab. e de bracatinga (Mimosa scabrella Benth.) pelo método de substituição da seiva. Ciência Florestal, 15(1), 75-86. http://dx.doi.org/10.5902/198050981825.

Silveira, A. G., Santini, E. J., Kulczynski, S. M., \& Trevisan, R. (2017). Atividade antifúngica do extrato natural da acácia-negra à Pycnoporus sanguineus. Scientia Forestalis, 45(114), 383-391. http://dx.doi.org/10.18671/scifor.v45n114.14

Sharma, S., Verma, M., \& Sharma, A. (2013). Utilization of non edible oil seed cakes as substrate for growth of Paecilomyces lilacinus and as biopesticide against termites. Waste and Biomass Valorization, 4(2), 325-330. http://dx.doi.org/10.1007/s12649-012-9134-6.

Venturoso, L., Bacchi, L. M. A., Gavassoni, W. L., Conus, L. A., Pontim, B. C. A., \& Bergamin, A. C. (2011). Atividade antifúngica de extratos vegetais sobre o desenvolvimento de fitopatógenos. Summa Phytopathologica, 37(1), 18-23. http://dx.doi.org/10.1590/S0100-54052011000100003.

Vidal, J. M., Evangelista, W. V., Silva, J. D. C., \& Jankowsky, I. P. (2015). Preservação de madeiras no Brasil: histórico, cenário atual e tendências. Ciência Florestal, 25(1), 257-271. http://dx.doi.org/10.5902/1980509817484.

Contribuição dos Autores: TM: Conceituação, Curadoria de Dados, Análise Formal, Investigação, Metodologia Escrita - Primeira Redação e Revisão e Edição; SAG: Conceituação, Análise Formal, Metodologia, Escrita- Revisão e Edição; BT: Conceituação, Escrita- Revisão e Edição; VG: Metodologia, Investigação; SJE: Conceituação, Metodologia, Escrita- Revisão e Edição. 